\title{
Efeitos de Histórias Experimentais e de Justificativas Sociais sobre o Comportamento de Seguir Regras
}

\author{
Effects of Experimental Stories and Social Justifications \\ on Rule Following Behavior
}

\author{
Lorena de Medeiros Sousa ${ }^{*}, a$, Carla Cristina Paiva Paracampo ${ }^{b} \&$ Luiz Carlos Albuquerque ${ }^{b}$ \\ ${ }^{a}$ Tribunal de Justiça do Estado do Pará, Belém, PA, Brasil \& 'buiversidade Federal do Pará, Belém, PA, Brasil
}

\begin{abstract}
Resumo
Este estudo avaliou o efeito de justificativas sobre o comportamento de seguir regras, quando foi construída uma história de reforço para não seguir regra. Dez crianças foram expostas a um procedimento de escolha segundo o modelo, cuja tarefa era tocar um de dois estímulos de comparação na presença de um estímulo contextual. Nas Condições I e II, as Fases 1, 2 e 4 eram iniciadas com a apresentação de instruções discrepantes das contingências programadas, cujo comportamento de segui-las produzia perda de fichas. Na Fase 3 era apresentada uma instrução correspondente com uma justificativa para seguir a instrução que produzia perda de fichas. A Condição I diferia da Condição II apenas com relação ao tipo de justificativa apresentada na Fase 3. Na Condição I era apresentada uma justificativa para ajudar crianças carentes e na Condição II uma justificativa que envolvia a aprovação do experimentador. O comportamento de nove dos 10 participantes ficou sob o controle da história de reforço para o não seguir instrução e das consequências imediatas produzidas pelo comportamento de não seguir instruções; o comportamento de um participante ficou sob o controle da justificativa para seguir a instrução correspondente.

Palavras-chave: Comportamento controlado por regras, histórias experimentais, justificativas sociais, perda de reforçadores.
\end{abstract}

\begin{abstract}
The effect of justifications on rule-following behavior after a history of reinforcement for not following rules was evaluated. Ten children were submitted to a matching to sample procedure such as the task was to touch one of two comparison stimuli in the presence of a contextual stimulus. In Conditions 1 and 2, the Phases 1, 2, and 4 begun with the presentation of an instruction that was discrepant to the contingencies; following the rule lead to the loss of tokens. In Phase 3 it was presented an instruction corresponding to the contingencies, with a justification for following the instruction that lead to the loss of tokens. The difference of Conditions 1 and 2 was only regarding to the justification presented in Phase 3. The justification presented in Condition 1 was "to help poor children" and in Condition 2 a justification regarding experimenter's approval. The behavior of 9 out of 10 participants was under control of the experimental history of reinforcement for not following instructions and of the immediate consequences produced by the behavior of not following instructions; the behavior of one participant was under control of the justification for following the corresponding instruction.

Keywords: Rule-governed behavior, experimental histories, social justifications, reinforcement loss.
\end{abstract}

Regras $^{1}$ são estímulos antecedentes verbais que podem descrever o comportamento e suas variáveis de controle;

\footnotetext{
"Endereço para correspondência: Rua dos Pariquis, 3045, Apto. 1002, Bairro Cremação, Belém, PA, Brasil 66040045. E-mail: lo_medeiros@hotmail.com,cparacampo@ gmail.com e lcalbu@ufpa.br

O manuscrito foi baseado na dissertação de mestrado da primeira autora, o qual foi submetido ao programa de Pós-Graduação em Teoria e Pesquisa do Comportamento, da Universidade Federal do Pará.

Este trabalho foi parcialmente financiado pelo Conselho Nacional de Desenvolvimento Científico e Tecnológico (CNPq), através de bolsa de mestrado da primeira autora. ${ }^{1}$ No presente estudo, o termo "regras" será utilizado de forma mais geral, referindo-se a uma classe de estímulos antecedentes verbais; o termo "instruções" será utilizado de forma mais restrita, nas descrições dos procedimentos e resultados de pesquisas, referindo-se a um estímulo antecedente verbal específico utilizado em um determinado estudo.
}

estabelecer a topografia de comportamentos novos; e, alterar as funções de estímulos, independentemente das consequências imediatas produzidas pelo comportamento e da contiguidade espaço-temporal entre estímulo-comportamento e estímulo-estímulo (L. C. Albuquerque, Paracampo, Matsuo, \& Mescouto, 2013; L. C. Albuquerque, Silva, \& Paracampo, 2014; Matsuo, Albuquerque, \& Paracampo, 2014; Paracampo, Albuquerque, Mescouto, \& Farias, 2013).

Por essa definição, quando o comportamento é controlado por regras, são as regras que determinam a topografia do comportamento, a sua probabilidade de ocorrer no futuro e, alteram as funções dos estímulos. Já quando o comportamento é controlado por contingências, são as consequências imediatas do comportamento que exercem essas 
funções. Nesse sentido, regras teriam funções similares às exercidas pelas contingências de reforço e, dessa forma, os efeitos de regras deveriam ser comparados com os efeitos de tais contingências (L. C. Albuquerque, 2001, 2005; L. C. Albuquerque, de Souza, Matos, \& Paracampo, 2003; L. C. Albuquerque \& Paracampo, 2010; L. C. Albuquerque et al., 2013; L. C. Albuquerque, Reis, \& Paracampo, 2008; L. C. Albuquerque et al., 2014).

No entanto, para Skinner (1969) regras podem evocar o comportamento por ela especificado, porém não alterariam a probabilidade de esse comportamento vir a ocorrer no futuro, uma vez que seriam as consequências que exerceriam tal função. Assim, o que determinaria se um ouvinte continuaria, ou não, seguindo uma regra, não seria a regra, mas a história de exposição às consequências diferenciais para o comportamento de seguir e de não seguir regras. Já para L. C. Albuquerque (2005) e L. C. Albuquerque e Paracampo (2010) regras podem alterar a probabilidade de o comportamento vir a ocorrer no futuro. De acordo com essa proposição, quando um falante apresenta uma regra, em geral, ele também apresenta justificativas para a regra ser ou não seguida. Por exemplo, suponha que um falante convide uma ouvinte para uma festa e que a ouvinte recuse o convite. Mas, o falante apresenta a justificativa de que fulano vai estar na festa e a ouvinte, então, diz que irá a festa. Nesse exemplo, a justificativa alteraria a probabilidade de a ouvinte ir à festa (L. C. Albuquerque et al., 2014; Matsuo et al., 2014; Paracampo, Albuquerque, Mescouto, et al., 2013)2.

De acordo com essa proposição, o comportamento de seguir regras ocorreria, não apenas devido a uma história de exposição a consequências imediatas diferenciais, mas

\footnotetext{
${ }^{2}$ Quatro aspectos devem ser esclarecidos. 1. As consequências futuras relatadas em regras são estímulos antecedentes verbais constituintes da regra e podem exercer controle sobre o comportamento no momento em que a regra é apresentada, quando a regra é ouvida ou lida. 2. Já o evento futuro relatado, não exerce controle sobre o comportamento porque esse evento não é produzido pelo comportamento no momento em que a regra é apresentada. Quando o evento relatado chega a ser produzido pelo comportamento, ele não é produzido como evento futuro, mas sim como uma consequência imediata do comportamento e é dessa forma que ele pode exercer controle. Desse modo, a regra funcionaria como substituto atual do evento futuro por ela relatado (L. C. Albuquerque, 2005; Paracampo, Albuquerque, Mescouto, et al., 2013). 3. Um comportamento e uma consequência futura podem fazer parte de uma contingência de reforço. Contudo, quando essa relação é descrita para um ouvinte e o comportamento especificado por essa regra ocorre, antes de entrar em contato com o evento relatado, tal comportamento deve ser considerado como controlado por regra (Paracampo, Albuquerque, Mescouto, et al., 2013). 4. Há duas formas principais de o falante indicar para o ouvinte que aprova ou não, o responder de acordo com uma regra: (a) por expressões faciais, críticas, elogios, etc., apresentados imediatamente após a ocorrência do comportamento; e, (b) por estímulos antecedentes verbais constituintes de regras, como: "Você deve fazer", "Eu quero que você faça"; "Faça o que você bem entender", "Todos vão ficar muito orgulhosos se você conseguir fazer", etc. Os efeitos da aprovação deveriam ser considerados como efeitos de contingências de reforço, no primeiro caso, e de regras, no segundo caso (L. C. Albuquerque et al., 2014).
}

também devido a uma história de exposição a justificativas diferenciais, para seguir e para não seguir regras. A diferença entre essas duas histórias é que, no primeiro caso, o seguimento de regras mantém contato com as suas consequências imediatas. Já no segundo caso, mantém contato com as justificativas relatadas para o seguimento da regra (L. C. Albuquerque \& Paracampo, 2010; L. C. Albuquerque et al., 2013; Matsuo et al., 2014; Paracampo, Albuquerque, Mescouto, et al., 2013).

Justificativas, então, são estímulos constituintes de uma regra que, quando manipulados, podem alterar a probabilidade de o comportamento relatado na regra vir a ocorrer no futuro (L. C. Albuquerque et al., 2013; L. C. Albuquerque et al., 2014; Matsuo et al., 2014; Najjar, Albuquerque, Ferreira, \& Paracampo, 2014; Paracampo, Albuquerque, Mescouto, et al., 2013). De acordo com esses autores, os principais tipos de justificativas são relatos antecedentes do falante acerca de:

1. As eventuais consequências do seguimento de regras; isto é, relatos que podem indicar se as consequências são aversivas ou reforçadoras, de grande ou de pequena magnitude, próximas ou futuras, passíveis de serem contatadas ou não etc. Por exemplo, um falante pode apresentar para um ouvinte a regra: "O trabalho que você tem de fazer é este" e acrescentar a seguinte justificativa do Tipo 1: "Fazendo isso, você ganhará mil reais no fim do mês".

2. A eventual aprovação do seguimento de regra; observada em relatos que podem indicar se o falante ou outras pessoas fazem questão, ou não, que a regra seja seguida. Por exemplo, um falante pode dizer: "Estude", e acrescentar a seguinte justificativa do Tipo 2: "Não me decepcione".

3. A confiança do falante; ou seja, relatos, tais como, "Eu acho", "Não estou certo", "Eu estou seguro", "Confie em mim" etc., que podem indicar se as consequências relatadas serão realmente produzidas, ou não, pelo seguimento de regra. Por exemplo, um falante pode apresentar a regra: "Invista em X" e acrescentar a seguinte justificativa do Tipo 3: "Pode confiar, esse investimento rende bem e é seguro".

4. A forma da regra; vista em relatos que podem indicar se a regra tem a forma de promessa, ordem, ameaça, acordo, discurso etc. Por exemplo, o falante pode dizer: "Não vá" e acrescentar as seguintes justificativas do Tipo 4: "Eu imploro"; "Isso é uma ordem" etc.

5. O que observar: relatos que podem indicar exemplos de comportamentos a serem seguidos ou não. Por exemplo, o falante pode dizer: "Pesquise sobre a idoneidade da loja antes de comprar" e acrescentar a seguinte justificativa do Tipo 5: "Fulano não pesquisou e olhe o prejuizo que ele teve".

O que há de comum em todos esses exemplos é que as justificativas são estímulos antecedentes verbais e podem interferir no seguimento de regras. Um exemplo adicional 
Sousa, L. M., Paracampo, C. C. P. \& Albuquerque, L. C. (2015). Efeitos de Histórias Experimentais e de Justificativas Sociais sobre o Comportamento de Seguir Regras.

pode tornar ainda mais clara essa proposição. Suponha que, em uma festa, um falante diga: "Prove $X$ " e que a ouvinte responda: "Não, vou provar Y que deve estar uma delícia”. O falante, então, acrescenta a seguinte justificativa: "Y está estragado, prove X que está muito bom". Nesse exemplo, as justificativas diferenciais para provar ' $\mathrm{X}$ ' $\mathrm{e}$ não provar ' $\mathrm{Y}$ ' alterariam a probabilidade de a ouvinte provar ' $X$ ' (L. C. Albuquerque et al., 2013; Matsuo et al., 2014; Paracampo, Albuquerque, Mescouto, et al., 2013).

Alguns estudos têm começado a investigar essa proposição. Por exemplo, Matsuo et al. (2014) expuseram 18 estudantes universitários a um procedimento de escolha de acordo com o modelo com o objetivo de investigar os efeitos de justificativas sobre o seguimento de regras. A tarefa era apontar para cada um dos três estímulos de comparação em sequência. Cada estímulo de comparação apresentava apenas uma dimensão - cor (C), espessura (E) ou forma (F) - em comum com o estímulo modelo e diferira nas demais. A sequência simples (EFC) e a sequência complexa (EFCFCE) eram as sequências corretas e as únicas a produzirem pontos (trocáveis por dinheiro) em esquema de reforço contínuo.

No Experimento 1, doze participantes foram distribuídos em quatro condições. Cada condição, realizada com três participantes, era constituída de cinco fases. A Fase 1, linha de base, era iniciada com a apresentação da instrução mínima e encerrada após a ocorrência de 10 tentativas. Cada uma das demais fases, de 20 tentativas, era iniciada com a apresentação da instrução com justificativa adicional ou da instrução sem justificativa adicional para a escolha da sequência complexa. A instrução sem justificativa adicional apresentava a mesma justificava (a promessa de concessão de pontos) para a escolha tanto da sequência simples quanto da sequência complexa. As instruções que apresentavam justificativas adicionais para o participante escolher a sequência complexa, especificavam que: (a) Ele ganharia o dobro dos ganhos (instrução com justificativa adicional financeira); (b) Ajudaria outras pessoas (instrução com justificativa adicional social); e, (c) Ganharia o dobro dos ganhos e ajudaria outras pessoas (instrução com justificativa adicional financeira e social). As condições diferiam apenas quanto à ordem em que as instruções com justificativa adicional ou sem justificativa adicional eram apresentadas para todos os participantes nas Fases 2, 3, 4 e 5.

No Experimento 2, procurou-se fazer, com seis novos participantes, uma replicação sistemática do Experimento 1 com o objetivo de avaliar os efeitos de justificativas sobre a manutenção do comportamento de escolher a sequência complexa na ausência de pontos imediatos.

Os resultados mostraram que:

1. Na ausência de instrução que especificasse sequências de respostas a serem apresentadas (caso da Fase 1), os participantes tenderam a apresentar um desempenho variável (isto é, tenderam a apresentar diferentes sequências) e nenhum emitiu a sequência complexa;
2. Nas fases em que a instrução apresentava a mesma justificava (a obtenção de pontos) tanto para a escolha da sequência simples quanto para a escolha da sequência complexa (instrução sem justificativa adicional), os participantes tenderam a apresentar a sequência simples; e,

3. Nas fases em que a instrução apresentava uma justificativa adicional (ganhar o dobro dos ganhos, ajudar os outros, ou ambas) para a escolha da sequência complexa, os participantes tenderam a apresentar a sequência complexa. De acordo com os autores os resultados apoiam a proposição de que regras podem alterar a probabilidade de o comportamento por ela especificado vir a ocorrer no futuro.

Nesta mesma linha de investigação, Castro, Paracampo e Albuquerque (no prelo) investigaram os efeitos de justificativas sobre o comportamento de seguir regras. Vinte crianças foram expostas a um procedimento de escolha de acordo com o modelo e distribuídas em quatro condições experimentais que diferiam quanto à justificativa utilizada e a fase em que a justificativa era apresentada. Nas Condições 1 e 2 as justificativas eram promessas de reforço de maior magnitude (comprar os brinquedos preferidos, se a instrução fosse seguida) e nas Condições 3 e 4, as justificativas eram promessas de reforço de menor magnitude (comprar os brinquedos menos preferidos, se a instrução não fosse seguida). Nas Fases 1, 3 e 5, de todas as condições, eram apresentadas instruções correspondentes às contingências programadas e o comportamento de segui-las era consequenciado com o ganho de fichas. Nas Fases 2 e 4, de todas as condições, ocorriam mudanças não sinalizadas nas contingências programadas e a manutenção do comportamento de seguir instrução era consequenciado com a perda de fichas. Os resultados mostraram que 16 dos 20 participantes deixaram de seguir instrução nas Fases 2 e 4, quando este comportamento passou a produzir perda de fichas, indicando que o controle pelas consequências imediatas programadas prevaleceu sobre o controle pelas justificativas apresentadas para a manutenção do seguimento de instruções.

Por outro lado, os resultados de três dos quatro participantes que seguiram instruções indicam que as justificativas relatadas em regras também podem contribuir para manter o seguimento de regras, mesmo quando este comportamento passa a produzir perda de reforçadores. Isso pode ser afirmado porque: (a) Dois desses quatro participantes, quando não foram expostos a justificativas adicionais na Fase 1, abandonaram o seguimento da instrução que produzia perda de reforço programado na Fase 2, mas quando foram expostos a justificativas adicionais na Fase 3, mantiveram o seguimento da instrução que produzia perda de reforço programado na Fase 4; e, (b) Um desses quatro participantes, quando foi exposto a justificativas adicionais na Fase 1, continuou seguindo a instrução na Fase 2 e quando não foi exposto a tais justificativas na Fase 3, abandonou o seguimento da instrução na Fase 4.

Dando continuidade a essa linha de investigação, 
no presente estudo, procurou- se comparar os efeitos de uma história de reforço do comportamento de não seguir regra discrepante das contingências e das consequências imediatas programadas para o seguimento de regras com os efeitos de justificativas do Tipo 1 (relatos que indicam as consequências do seguir regras) e do Tipo 2 (relatos que indicam se o falante aprova, ou não, o seguimento de regra), tanto sobre o comportamento de seguir regra correspondente que produz perda do reforço programado (fichas trocáveis por brinquedos), quanto sobre o comportamento de seguir regra discrepante das contingências programadas que também produz perda do reforço programado.

Para tanto, crianças foram expostas a uma versão do procedimento de escolha de acordo com o modelo desenvolvido por Paracampo (1991). Os participantes foram distribuídos em duas condições, com quatro fases cada. Nas duas condições, nas Fases 1 e 2 foi construída uma história de reforço do comportamento de não seguir regra discrepante das contingências; na Fase 3 da Condição 1 foi apresentada a regra correspondente com a justificativa do Tipo 1, que descrevia que se o participante emitisse o comportamento por ela especificado ele perderia fichas trocáveis por brinquedos, mas as fichas perdidas seriam doadas para crianças carentes; na Fase 3 da Condição 2 foi apresentada a regra correspondente com a justificativa do Tipo 2, que descrevia que se o participante emitisse o comportamento por ela especificado ele perderia fichas trocáveis por brinquedos, mas o experimentador ficaria muito feliz se a regra fosse seguida; e, na Fase 4 das duas condições, foi apresentada uma regra discrepante das contingências.

Assim, se o controle pela história de reforço para o não seguimento de regra e o controle pelas consequências imediatas programadas pode superar o controle por justificativas, deveria ser esperado que o seguimento de regra fosse abandonado nas Fases 3 e 4. Por outro lado, se o controle por justificativas pode superar o controle pela história de reforço para o não seguimento de regra e o controle pelas consequências imediatas programadas, deveria ser esperado que o seguimento de regra fosse mantido nas Fases 3 e 4 das duas condições.

\section{Método}

\section{Participantes}

Participaram do estudo 10 crianças, com idades variando entre sete e nove anos, cursando o segundo ou terceiro ano do Ensino Fundamental, de uma escola particular. Só participaram do estudo as crianças que concordaram em participar e que tiveram sua participação previamente autorizada pelos responsáveis por meio da assinatura do Termo de Consentimento Livre e Esclarecido.

\section{Material e Equipamentos}

Foi utilizada uma mesa retangular cujo tampo tinha uma abertura de 49,5 x 49,5 cm, coberta por uma placa de acrílico leitoso, sob a qual ficavam quatro lâmpadas fluorescentes de 20 watts, uma de cor verde, uma de cor vermelha, uma de cor amarela e uma de cor azul. Separando o experimentador do participante, sobre a mesa, havia um anteparo de madeira de $14 \mathrm{~cm}$ de altura e 69,5 $\mathrm{cm}$ de comprimento. Atrás do anteparo, ao lado do experimentador, ficavam os arranjos de estímulos previamente preparados, e um conjunto de interruptores para o controle das lâmpadas fluorescentes.

Foram utilizados como estímulos discriminativos e condicionais 45 desenhos coloridos de objetos conhecidos das crianças (por exemplo, uma bola, uma lua, uma meia etc.). Esses desenhos de $5 \times 5 \mathrm{~cm}$ cada, eram impressos em cartões de cartolina que eram colados em folhas de papel cartão de $14 \times 14 \mathrm{~cm}$, de maneira a formar 30 diferentes arranjos de estímulos.

Cada arranjo de estímulos continha três cartões com desenhos; dois desenhos eram sempre iguais entre si e o terceiro era diferente. Um cartão contendo um dos desenhos iguais era colado no topo da folha (estímulo-modelo) e os outros dois mais abaixo e lado a lado (estímulos de comparação). A combinação dos estímulos era aleatória, assim como a ordem de apresentação dos 30 arranjos. Como estímulos contextuais foram utilizados lâmpadas coloridas acesas, e como estímulos reforçadores, fichas pretas que poderiam ser trocadas por brinquedos e guloseimas. Duas vasilhas de plástico foram utilizadas para guardar as fichas. Uma vasilha ficava sobre o anteparo ao lado direito do experimentador e a outra sobre o tampo da mesa próxima ao participante.

As respostas dos participantes eram registradas pelo experimentador em um protocolo de registro previamente preparado e eram também gravadas em vídeo, para análises posteriores. A coleta de dados foi realizada em uma sala da escola em que os participantes estudavam. Na sala, além da mesa experimental, havia uma mesa, visível ao participante, sobre a qual ficavam expostos diversos brinquedos e guloseimas.

\section{Procedimento}

Após ser convidada a participar de um jogo, a criança era conduzida à sala experimental pelo experimentador. Ao entrar na sala o experimentador mostrava à criança uma mesa sobre a qual ficavam expostos diversos brinquedos e guloseimas (cada item tinha uma etiqueta afixada indicando o número de fichas que valia). Em seguida, apresentava, oralmente, as seguintes instruções preliminares: "Eu te trouxe aqui para nós brincarmos de um jogo. No jogo nós temos esta lojinha com vários brinquedos. Estes brinquedos podem ser comprados com fichas como estas aqui" (o experimentador mostrava cinco fichas ao participante).

Por exemplo, este carrinho vale 10 fichas, esta boneca vale 20 fichas. Durante o jogo você poderá ganhar muitas fichas e no final do jogo você poderá vir aqui na lojinha e comprar brinquedos com suas fichas. Quanto mais fichas você ganhar, mais brinquedos você poderá comprar. Entendeu? [Esta instrução era repetida mais uma vez] 
Sousa, L. M., Paracampo, C. C. P. \& Albuquerque, L. C. (2015). Efeitos de Histórias Experimentais e de Justificativas Sociais sobre o Comportamento de Seguir Regras.

Em seguida, o experimentador dizia: “Agora eu vou te mostrar como se compra na lojinha. Eu vou te dar cinco fichas para você fazer uma compra na lojinha. Vamos ver o que você pode comprar com cinco fichas?". Após o participante fazer a compra o experimentador dizia: "Agora vamos para aquela mesa que eu vou te explicar como é o jogo". Participante e experimentador se dirigiam à mesa experimental, com o participante levando o brinquedo que comprou, e era dado o início à sessão experimental.

No início da sessão experimental, participante e experimentador ficavam sentados à mesa experimental, frente a frente. $\mathrm{O}$ experimentador apresentava oralmente ao participante uma instrução e, logo após, passava a apresentar os arranjos de estímulos. Em cada tentativa, um arranjo de estímulos, constituído de um estímulo modelo e dois de comparação, era apresentado ao participante e, em seguida, uma das lâmpadas era acesa. Na presença desses estímulos o participante deveria tocar com o dedo apenas um dos estímulos de comparação. Caso a resposta estivesse de acordo com as contingências programadas (resposta correta), ocorria o seguinte: nenhuma ficha era retirada da vasilha do participante, a lâmpada era apagada, o arranjo de estímulos retirado, um novo arranjo era apresentado e outra lâmpada era acesa, iniciando uma nova tentativa. Caso a resposta não estivesse de acordo com as contingências programadas (resposta incorreta), ocorria o seguinte: uma ficha era retirada do total de fichas do participante, a lâmpada era apagada, o arranjo de estímulos era retirado, um novo arranjo era apresentado e outra lâmpada era acesa, iniciando uma nova tentativa. Cada arranjo ficava disponível para o participante por no máximo $5 \mathrm{~s}$, tempo gasto pelo experimentador nas tarefas de tirar um arranjo de estímulos e apresentar outro. Imediatamente após o participante emitir a resposta de tocar um dos estímulos de comparação, ou se o participante não emitisse a resposta requisitada de tocar, passados esses $5 \mathrm{~s}$, era iniciada uma nova tentativa.

Os participantes foram distribuídos em duas condições experimentais, conforme a Tabela 1. Cada condição era constituída de quatro fases.

Tabela 1

Descrição do Procedimento

\begin{tabular}{|c|c|c|c|c|}
\hline & Fase 1 & Fase 2 & Fase 3 & Fase 4 \\
\hline Condições ИI & $\begin{array}{l}\text { Instrução } \\
\text { discrepante }\end{array}$ & $\begin{array}{l}\text { Instrução } \\
\text { discrepante }\end{array}$ & $\begin{array}{l}\text { Instrução } \\
\text { correspondente }\end{array}$ & $\begin{array}{l}\text { Instrução } \\
\text { discrepante }\end{array}$ \\
\hline Respostas instruídas & Vermelho $=$ Amarelo $\#$ & Verde $=$ Azul \# & Amarelo $=$ Verde $\#$ & Azul $=$ Vermelho \# \\
\hline Respostas reforçadas & Vermelho \# Amarelo = & Verde \# Azul = & Amarelo \# Verde $=$ & Azul \# Vermelho = \\
\hline $\begin{array}{l}\text { Consequências programadas } \\
\text { para o seguir instrução }\end{array}$ & Retirada de fichas & Retirada de fichas & Retirada de fichas & Retirada de fichas \\
\hline $\begin{array}{l}\text { Consequências programadas } \\
\text { para o não seguir instrução }\end{array}$ & $\begin{array}{l}\text { Não retirada } \\
\text { de fichas }\end{array}$ & $\begin{array}{l}\text { Não retirada } \\
\text { de fichas }\end{array}$ & $\begin{array}{l}\text { Não retirada } \\
\text { de fichas }\end{array}$ & $\begin{array}{l}\text { Não retirada } \\
\text { de fichas }\end{array}$ \\
\hline
\end{tabular}

Nota. As cores representam as luzes que indicavam as respostas que os participantes deveriam emitir. O símbolo $=($ igual $)$ representa a resposta de escolha do estímulo de comparação igual do modelo. O símbolo \# (diferente) representa a resposta de escolha do estímulo de comparação diferente do modelo. O sombreamento indica a fase em que era apresentada uma justificativa social para ajudar os outros (Condição I) e uma justificativa social que envolvia a aprovação do experimentador (Condição II).

Condição I. Nesta condição, procurou-se verificar, principalmente, se o comportamento de seguir instrução correspondente às contingências programadas (uma regra é correspondente às contingências quando o comportamento de segui-la produz as consequências por ela descritas) é mantido quando:

1. O seguimento dessa instrução correspondente produz perda do reforço programado (fichas trocáveis por brinquedos);

2. A instrução correspondente apresenta uma justificativa do Tipo 1 (relatos que indicam as consequências do seguimento de regras) para a emissão do comportamento por ela descrito; em outras palavras, especifica que se o participante emitir o comportamento por ela especificado, ele perderá fichas, mas as fichas perdidas serão doadas para crianças carentes; e,

3. Antes de ser exposto à instrução correspondente, o participante é exposto a uma história experimental de reforço para o não seguimento de instrução discrepante das contingências.

Assim, nas Fases 1 e 2, procurou-se construir uma história de reforço programado do comportamento de não seguir instrução discrepante. Para tanto, nessas duas fases (Fases 1 e 2), o participante era exposto a uma instrução discrepante das contingências programadas cujo comportamento de segui-la produzia perda do reforço programado e o comportamento de não segui-la evitava a perda de tal reforço. Na Fase 3, procurou-se avaliar os efeitos da história construída nas Fases 1 e 2 e avaliar os efeitos de justifi- 
cativas do Tipo 1 (relatos que indicam as consequências do seguir regras) sobre o seguimento da regra correspondente. Na Fase 3, então, o participante era exposto a uma instrução correspondente às contingências, que especificava que se o participante emitisse o comportamento por ela descrito, ele perderia fichas, mas as fichas perdidas seriam doadas para crianças carentes (Justificativas do Tipo 1). Na Fase 4, procurou-se avaliar os efeitos das histórias das Fases 1,2 e 3 sobre o seguimento da mesma regra discrepante apresentada nas Fases 1 e 2.

A Fase 1 era iniciada com o experimentador apresentando, oralmente, ao participante a seguinte instrução discrepante: "O jogo começa com você ganhando 80 fichas" (o experimentador entregava 80 fichas para o participante). Em seguida dizia: "O objetivo do jogo é você não perder fichas para depois comprar brinquedos naquela lojinha. Você perde uma ficha cada vez que eu tiro uma ficha da sua vasilha e coloco na minha" (no presente estudo todas as vezes que esta frase era dita, o experimentador retirava uma ficha da vasilha do participante e a colocava em sua vasilha). Depois era dito: "Agora, eu vou te explicar o que você deve fazer para não perder fichas". O experimentador apresentava ao participante um arranjo de estímulos, e em seguida apontava para o cartão modelo e dizia: "Este é o cartão-mãe. Toque com o dedo o cartão-mãe". Após o participante tocar com o dedo o cartão-mãe, o experimentador apontava para os dois cartões de comparação e dizia: "Estes são os cartões-filhos. Toque com o dedo os cartões-filhos". Após o participante tocar com o dedo os cartões-filhos, o experimentador acendia a luz vermelha e dizia: "Quando a mesa ficar vermelha, você deve tocar com o dedo o filho que é igual à mãe. A mesa está vermelha, toque com o dedo o filho que é igual à mãe”. Após o participante tocar, o experimentador dizia: "Fazendo isso, você não perderá fichas". Em seguida, o experimentador acendia a luz amarela e dizia: "Quando a mesa ficar amarela, você deve tocar com o dedo o filho que é diferente da mãe. A mesa está amarela, toque com o dedo o filho que é diferente da mãe". Após o participante tocar, o experimentador dizia: "Fazendo isso, você não perderá fichas". Esta instrução era apresentada mais uma vez ao participante e, em seguida, eram feitas as seguintes perguntas ao participante: "Agora me diga o que você deve fazer para não perder fichas quando a mesa ficar vermelha?" e "Agora me diga o que você deve fazer para não perder fichas quando a mesa ficar amarela?". Durante esta fase, o seguimento da instrução discrepante (isto é, a emissão das respostas especificadas por essa instrução) era consequenciado com a perda de fichas. O não seguimento da instrução discrepante (isto é, a emissão das respostas opostas às descritas nessa instrução), evitava a perda de fichas.

No início das Fases 2 e 4 o experimentador apresentava oralmente ao participante uma instrução discrepante similar à da Fase 1, exceto: (a) Pela omissão do seguinte trecho do início da instrução: "Este é o cartão-mãe. Toque com o dedo o cartão-mãe". Estes são os cartões-filhos. Toque com o dedo os cartões-filhos" e, (b) Pelo fato de que esta instrução especificava outras respostas para evitar a perda de fichas. Na Fase 2, para evitar a perda de fichas, a instrução discrepante especificava que o participante deveria apontar para o filho igual a mãe quando a luz verde estivesse acesa e para o filho diferente da mãe quando a luz azul estivesse acesa. Na Fase 4, para evitar a perda de fichas, a instrução discrepante especificava que o participante deveria apontar para o igual quando a luz azul estivesse acesa e para o diferente quando a luz vermelha estivesse acesa. No entanto, durante as Fases 2 e 4, o seguimento de instrução produzia perda de ficha e o não seguimento de instrução evitava a perda de ficha.

No início da Fase 3, o experimentador apresentava oralmente ao participante a seguinte instrução correspondente: "Quando a mesa ficar amarela, você deve tocar com o dedo o filho que é igual à mãe. A mesa está amarela, toque com o dedo o filho que é igual à mãe". "Fazendo isso, você perde uma ficha que eu tiro da sua vasilha e coloco na minha". "Quando a mesa ficar verde, você deve tocar com o dedo o filho que é diferente da mãe. A mesa está verde, toque com o dedo o filho que é diferente da mãe". "Fazendo isso, você perde uma ficha que eu tiro da sua vasilha e coloco na minha". "Se você fizer o que eu disse, você perderá fichas, mas essas fichas que você perder serão doadas para crianças carentes trocarem por brinquedos na lojinha". Durante esta fase o seguimento da instrução correspondente produzia perda de ficha e o não seguimento dessa instrução evitava a perda de ficha.

Condição II. A Condição II era idêntica à Condição I, exceto por uma única diferença. Na Condição II a justificativa adicional para a instrução correspondente ser seguida na Fase 3 era do Tipo 2 (relatos que indicam se o falante aprova, ou não, o seguimento de regra) e especificava o seguinte: "Se você fizer o que eu disse, você perderá fichas, mas eu ficarei muito feliz com o seu comportamento".

Em todas as fases das duas condições, após a apresentação das instruções, eram feitas perguntas aos participantes solicitando que estes descrevessem o que deveriam fazer para não perder fichas e deixar o experimentador feliz ou para ajudar crianças carentes, quando determinada luz estivesse acesa. Só eram expostos às fases seguintes, os participantes que respondessem corretamente as duas perguntas. Nas duas condições a transição entre fases era marcada pela mudança nas contingências programadas e pela apresentação de uma nova instrução. Todas as fases das duas condições eram encerradas quando um de dois critérios fosse atingido, o que ocorresse primeiro: (a) a emissão de 10 respostas consecutivas e corretas ou, (b) apresentação de 20 tentativas. Em todas as fases das duas condições, quando uma luz estava acesa a outra estava apagada. As luzes eram apresentadas aleatoriamente ao longo das tentativas, garantindo-se que as duas fossem apresentadas o mesmo número de vezes em cada fase. Cada participante foi exposto a uma única sessão que durava aproximadamente 40 minutos. Ao término da sessão o participante era conduzido à lojinha para trocar as fichas por brinquedos. 
Sousa, L. M., Paracampo, C. C. P. \& Albuquerque, L. C. (2015). Efeitos de Histórias Experimentais e de Justificativas Sociais sobre o Comportamento de Seguir Regras.

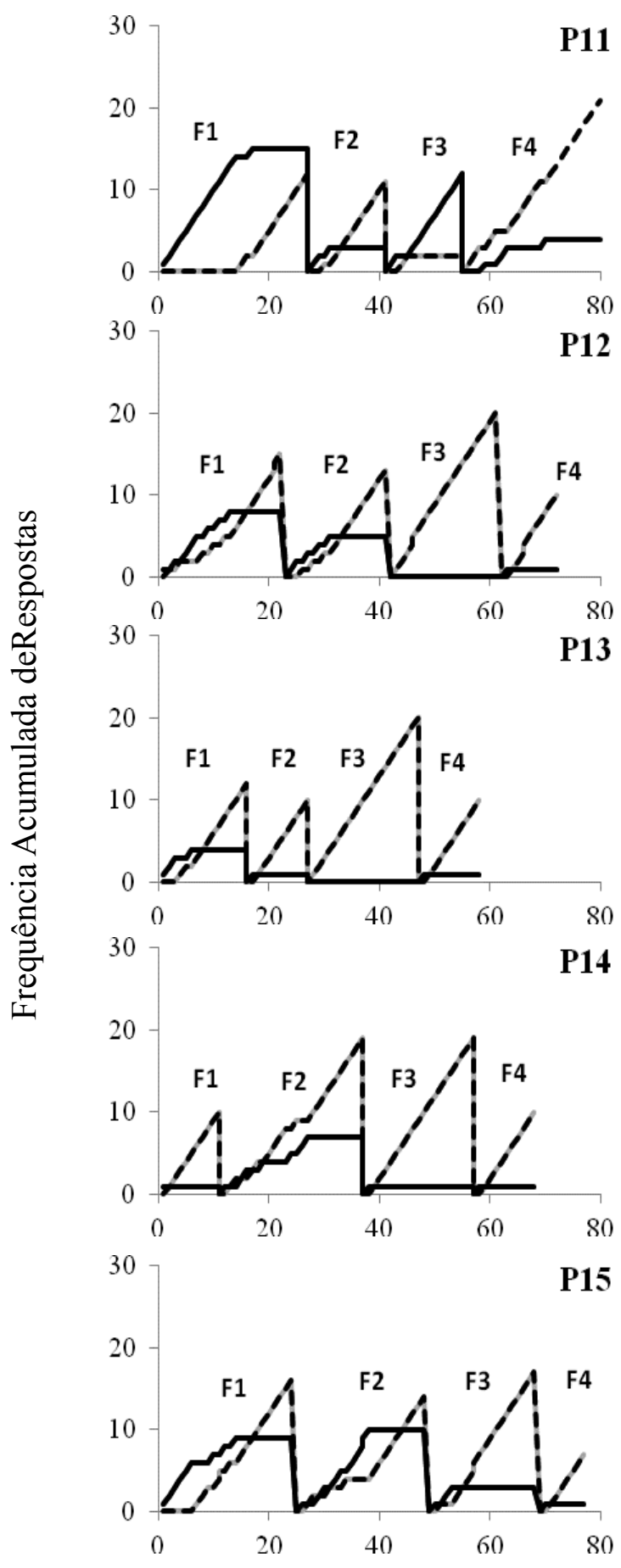

Tentativas

Figura 1. Frequência acumulada de respostas de seguimento de instrução (linha sólida) e de não seguimento de instrução (linha tracejada), para cada participante da Condição I, durante cada fase (F) experimental. Quebras na curva acumulada indicam mudanças de fase. Nas Fases 1, 2 e 4 eram apresentadas instruções discrepantes às contingências programadas para cada Fase, cujas respostas produziam perda de fichas, enquanto que o não seguimento da instrução discrepante evitava perda de fichas. Já na Fase 3 era apresentada uma instrução correspondente (que especificava respostas que produziam perda de fichas) com uma justificativa social (ajudar os outros) para o seguimento da instrução correspondente.

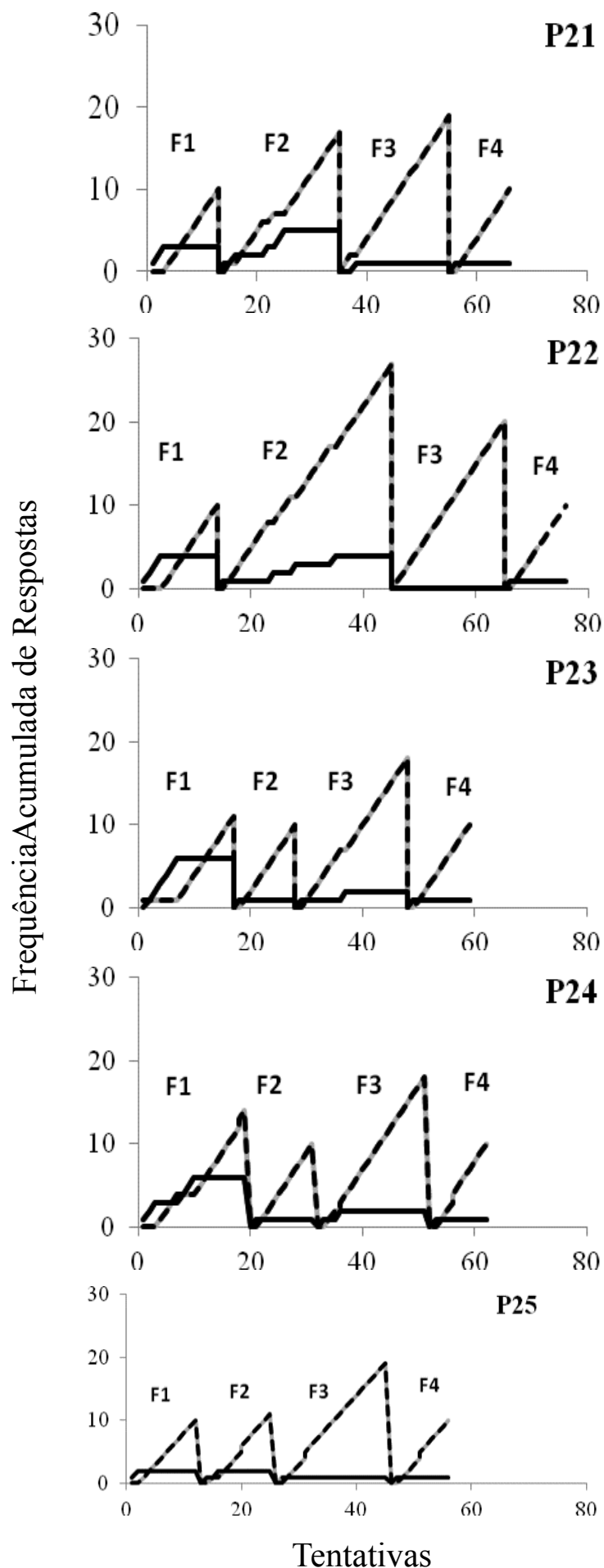

Figura 2. Frequência acumulada de respostas de seguimento de instrução (linha sólida) e de não seguimento de instrução (linha tracejada), para cada participante da Condição II, durante cada fase (F) experimental. Quebras na curva acumulada indicam mudanças de fase. Nas Fases 1, 2 e 4 eram apresentadas instruções discrepantes das contingências programadas para cada Fase, cujas respostas produziam perda de fichas, enquanto que o não seguimento da instrução discrepante evitava perda de fichas. Já na Fase 3 era apresentada uma instrução correspondente (que especificava respostas que produziriam perda de fichas) com uma justificativa social (aprovação do experimentador) para o seguimento da instrução correspondente. 


\section{Resultados}

Todos os participantes das duas condições responderam corretamente quando solicitados a verbalizar a tarefa que deveriam desempenhar. As Figuras 1 e 2 apresentam a frequência acumulada das respostas emitidas pelos participantes expostos às Condições I e II, respectivamente.

Nas Figuras 1 e 2, observa-se que todos os participantes, exceto P11 (Fase 4), iniciaram as Fases 1 e 2 das Condições I e II seguindo a instrução discrepante, mas depois deixaram de seguir essa instrução e passaram a responder de acordo com as contingências programadas para o não seguimento de regra em cada fase.

Na Fase 3 da Condição I, quando foi apresentada a justificativa do Tipo 1 (relatos que indicavam as consequências do seguimento de regras, isto é, que indicavam que o seguimento da regra beneficiaria outras pessoas) para o seguimento da instrução correspondente, apenas o Participante P11 seguiu a instrução correspondente, de acordo com a justificativa apresentada, mesmo perdendo fichas. Os Participantes P12 e P13 não seguiram a instrução correspondente durante as 20 tentativas da Fase 3. Os Participantes $\mathrm{P} 14$ e P15 deixaram de seguir essa instrução e passaram a responder sob o controle das consequências imediatas produzidas pelo comportamento de não seguir instrução.

Na Fase 3 da Condição II, quando foi apresentada a justificativa do Tipo 2 (relatos que indicavam que o experimentador aprovava o seguimento da regra, isto é, que indicavam que o experimentador ficaria muito feliz se a regra fosse seguida) para o seguimento da instrução correspondente, nenhum participante apresentou um desempenho sob o controle da justificativa do Tipo 2, isto é, os participantes não seguiram a instrução correspondente. $\mathrm{Na}$ Fase 4, todos os participantes, inclusive P11, deixaram de seguir a regra discrepante.

\section{Discussão}

O presente estudo procurou verificar se justificativas podem manter o seguir regras, mesmo quando esse comportamento produz perda do reforço programado (fichas trocáveis por brinquedos). Para tanto, 10 crianças foram expostas, inicialmente, a uma história de reforço para o não seguir regra e, em seguida, a justificativas para a emissão do comportamento de seguir uma regra que produzia a perda do reforço programado. Para cinco participantes, a justificativa era ajudar outras pessoas (justificativa do Tipo 1 - relatos que indicam as consequências do seguir regras) e para cinco outros participantes, a justificativa era obter a aprovação do experimentador (justificativa do Tipo 2 - relatos que indicam se o falante aprova, ou não, o seguir regra). Apenas um dos cinco participantes, exposto à justificativa de ajudar outras pessoas, seguiu sistematicamente a regra que levava à perda do reforço programado. Nenhum dos participantes exposto à justificativa de agradar o experimentador seguiu a regra.
Tais resultados indicam que o controle pela história experimental de reforço para o não seguir regra e pelas consequências imediatas diferenciais para seguir e para não seguir regra superou o controle pelas justificativas para seguir regras. Portanto, em adição às evidências experimentais que sugerem que o comportamento de seguir regras que produz perda do reforço programado tende a ser abandonado, mesmo quando o participante é classificado de inflexível (Pinto, Paracampo, \& Albuquerque, 2008) e mesmo quando o seguir regras é monitorado pela presença de um observador (N. M. A. Albuquerque, Paracampo, \& Albuquerque, 2004), os resultados do presente estudo sugerem que o seguir regras que produz perda do reforço programado, também tende a ser abandonado, mesmo quando o participante é exposto a justificativas para que a regra seja seguida.

Mas, os dados do Participante P11 (Condição I) sugerem que justificativas podem chegar a determinar a manutenção do seguir regra que produz perda do reforço programado. Isso, contudo, não esclarece por que no presente estudo as justificativas não exerceram controle sobre o comportamento de um número maior de participantes. Respostas a essa questão podem ser encontradas quando os resultados do presente estudo e do estudo de Matsuo et al. (2014) são comparados.

No presente estudo, os participantes tenderam a deixar de seguir regra, independentemente das justificativas; já no Experimento 2 do estudo de Matsuo et al. (2014), tenderam a seguir regra sob o controle de justificativas,independe ntemente das consequências imediatas. Essa diferença de resultados pode ter ocorrido devido, em parte, às diferenças entre as consequências imediatas produzidas pelo seguir regra nesses estudos. No Experimento 2 do estudo de Matsuo et al. (2014), a consequência imediata era a não obtenção do reforço programado (pontos trocáveis por dinheiro) e no presente estudo era a perda do reforço programado (fichas trocáveis por brinquedos). Essa sugestão está de acordo, tanto com a proposição de que o seguir regras tem maior probabilidade de ser abandonado quando produz consequências imediatas aversivas do que quando produz outros tipos de consequências imediatas (Baron \& Galizio, 1983; Chase \& Danforth, 1991; Galizio, 1979; LeFrancois, Chase, \& Joyce, 1988; Paracampo \& Albuquerque, 2004; Paracampo, Albuquerque, \& Farias, 2013; Paracampo, Albuquerque, Farias, Carvalló, \& Pinto, 2007); quanto com a proposição de que a manutenção do comportamento de seguir regras depende, em parte, do tipo de consequência imediata por ele contatada (Paracampo \& Albuquerque, 2004; Paracampo, Albuquerque, \& Farias, 2013; Paracampo et al., 2007).

Por exemplo, no estudo conduzido por Castro et al. (no prelo), tal como ocorreu no presente estudo, 16 de 20 participantes não apresentaram um desempenho sob o controle das justificativas. Neste estudo, a consequência imediata produzida pelo seguir regra de acordo com a justificativa também era a perda de fichas trocáveis por brinquedos, o que sustenta a análise feita previamente 
Sousa, L. M., Paracampo, C. C. P. \& Albuquerque, L. C. (2015). Efeitos de Histórias Experimentais e de Justificativas Sociais sobre o Comportamento de Seguir Regras.

de que é mais provável que participantes emitam comportamentos com baixa probabilidade de ocorrência sob o controle de justificativas para emiti-los quando este comportamento apenas deixa de produzir reforços (Matsuo et al., 2014) do que quando produz perda de reforços (Castro et al., no prelo).

Além das diferenças entre as consequências imediatas produzidas pelo seguir regras, as diferenças entre as histórias experimentais dos participantes também podem ter contribuído para a ocorrência das diferenças dos resultados dos estudos em análise. Mais especificamente, diferente do estudo de Matsuo et al. (2014), no presente estudo, os participantes também podem não ter feito o que as justificativas recomendavam que deveria ser feito, devido às suas histórias experimentais de reforço para não seguir regras apresentadas pelo mesmo falante que apresentou as justificativas. Essa história pode ter tornado o falante (o experimentador) "não confiável", isto é, uma pessoa que não faz o que diz que iria fazer. Assim, no presente estudo, além da perda do reforço programado, é possível que os participantes não tenham seguido regra, também porque, de acordo com práticas culturais, o experimentador não apresentava méritos para ser agradado e as justificativas por ele apresentadas não garantiam que as fichas perdidas seriam realmente doadas para outras pessoas.

Em síntese, pode-se sugerir que os efeitos de justificativas sobre a ocorrência e manutenção do comportamento de seguir regras dependem mais da combinação entre o conjunto de condições favoráveis ao controle pelas contingências programadas e o conjunto de condições não favoráveis ao controle pela regra, do que uma ou outra condição isoladamente (L. C. Albuquerque et al., 2003; L. C. Albuquerque et al., 2013; L. C. Albuquerque, Reis, \& Paracampo, 2006; L. C. Albuquerque et al., 2014; Monteles, Paracampo, \& Albuquerque, 2006). Com base nessa proposição, quanto maior o número de condições favoráveis, em relação ao número de condições não favoráveis, a emissão e a manutenção do comportamento de seguir regras, maior a probabilidade de esse comportamento ser mantido e vice e versa.

Neste sentido, é provável que a maioria dos participantes do presente estudo não tenha apresentado um desempenho sob o controle das justificativas apresentadas, porque o conjunto de condições não favoráveis à emissão do comportamento sob o controle da justificativa era maior do que o conjunto de condições favoráveis. Por exemplo, nas Condições I e II seriam consideradas condições desfavoráveis: (a) A história de reforço para o não seguir regra discrepante (Fases 1 e 2); e, (b) As consequências imediatas produzidas pelo comportamento de seguir regra (perda de fichas), para o qual a justificativa era apresentada. A única condição favorável era a presença do experimentador monitorando o desempenho dos participantes.

Por fim, é importante que pesquisas futuras continuem investigando o papel de justificativas relatadas nas regras com o objetivo de esclarecer os efeitos isolados e com- binados de algumas das variáveis aqui apontadas sobre a probabilidade de ocorrência de comportamentos sob o controle de justificativas. A realização de novos estudos nessa linha de pesquisa pode contribuir para ampliar o conhecimento já existente acerca da função das propriedades formais das regras sobre o estabelecimento e manutenção do comportamento de seguir regras, constituindo-se num recurso para a comunidade verbal aumentar a probabilidade de emissão de comportamentos com baixa probabilidade de ocorrência.

\section{Referências}

Albuquerque, L. C. (2001). Definições de regras. In H. J. Guilhardi, M. B. B. P. Madi, P. P. Queiroz, \& M. C. Scoz (Eds.), Sobre comportamento e cognição: Expondo a variabilidade (pp. 132-140). Santo André, SP: ARBytes.

Albuquerque, L. C. (2005). Regras como instrumento de análise do comportamento. In L. C. Albuquerque (Ed.), Estudos do comportamento (pp. 143-176). Belém, PA: Editora da Universidade Federal do Pará.

Albuquerque, L. C., de Souza, D. G., Matos, M. A., \& Paracampo, C. C. P. (2003). Análise dos efeitos de histórias experimentais sobre o seguimento subsequente de regras. Acta Comportamentalia, 11, 87-126.

Albuquerque, L. C., \& Paracampo, C. C. P. (2010). Análise do controle por regras. Psicologia USP, 21, 253-273. doi:10.1590/S0103-65642010000200004

Albuquerque, L. C., Paracampo, C. C. P., Matsuo, G. L., \& Mescouto, W. A. (2013). Variáveis combinadas, comportamento governado por regras e comportamento modelado por contingência. Acta Comportamentalia, 21, 285-304.

Albuquerque, L. C., Reis, A. A., \& Paracampo, C. C. P. (2006). Efeitos de uma história de reforço contínuo sobre o seguimento de regra. Acta Comportamentalia, 14, 47-75.

Albuquerque, L. C., Reis, A. A., \& Paracampo, C. C. P. (2008). Efeitos de histórias de reforço, curtas e prolongadas, sobre o seguimento de regras. Acta Comportamentalia, 16, 305-332.

Albuquerque, L. C., Silva, L. S., \& Paracampo, C. C. P. (2014). Análises de variáveis que podem interferir no comportamento de seguir regras discrepantes. Acta Comportamentalia, 22, $51-71$.

Albuquerque, N. M. A., Paracampo, C. C. P., \& Albuquerque, L. C. (2004). Análise do papel de variáveis sociais e de consequências programadas no seguimento de instruções. Psicologia: Reflexão e Crítica, 17, 31-42.

Baron, A., \& Galizio, M. (1983). Instructional control of human operant behavior. The Psychological Record, 33, 495-520.

Castro, J. L., Paracampo, C. C. P., \& Albuquerque, L. C. (no prelo). Efeitos de promessas de reforço de maior e menor magnitude sobre o seguir instruções em crianças. Acta Comportamentalia.

Chase, P., \& Danforth, J. (1991). The role of rules in concept learning. In L. Hayes \& P. Chase (Eds.), Dialogues on verbal behavior (pp. 205-225). Hillsdale, NJ: Lawrence Erlbaum.

Galizio, M. (1979). Contingency-shaped and rule-governed behavior: Instructional control of human loss avoidance. Journal of the Experimental Analysis of Behavior, 31, 53-70.

LeFrancois, J. R., Chase, P. N., \& Joyce, J. H. (1988). The effects of variety of instructions on human fixed-interval performance. Journal of the Experimental Analysis of Behavior, 49, 383-393. 
Matsuo, G. L., Albuquerque, L. C. de, \& Paracampo, C. C. P. (2014). Efeitos do contato com justificativas relatadas em regras sobre o seguir regras. Acta Comportamentalia, 22, 273-293.

Monteles, K. M. C., Paracampo, C. C. P., \& Albuquerque, L. C. (2006). Efeitos de uma história de reforço contínuo e de consequências sociais sobre o seguir regras. Psicologia: Reflexão e Crítica, 19, 186-196.

Najjar, E. C. A., Albuquerque, L. C., Ferreira, E. A. P., \& Paracampo, C. C. P. (2014). Efeitos de regras sobre relatos de comportamentos de cuidados com os pés em pessoas com diabetes. Psicologia: Reflexão e Crítica, 27, 341-350. doi:10.1590/1678-7153.201427215

Paracampo, C. C. P. (1991). Alguns efeitos de estímulos antecedentes verbais e reforçamento programado no seguimento de regra. Psicologia: Teoria e Pesquisa, 7, 149-161.

Paracampo, C. C. P., \& Albuquerque, L. C. (2004). Análise do papel das consequências programadas no seguimento de regras. Interação em Psicologia, 8, 237-245. doi:10.5380/ psi.v8i2.3259

Paracampo, C. C. P., Albuquerque, L. C., \& Farias, A. F. (2013). Efeitos das consequências verbais sobre o seguir regras. Acta Comportamentalia, 21, 159-173.

Paracampo, C. C. P., Albuquerque, L. C., Farias, A. F., Carvalló, B. N., \& Pinto, A. R. (2007). Efeitos de consequências programadas sobre o comportamento de seguir regras. Interação em Psicologia, 11, 161-173. doi:10.5380/psi.v11i2.7850

Paracampo, C. C. P., Albuquerque, L. C., Mescouto, W. A., \& Farias, A. F. (2013b). Efeitos de perguntas e de respostas às perguntas sobre o seguir regras apresentadas em uma história infantil. Psicologia: Teoria e Pesquisa, 29, 369-379. doi:10.1590/S0102-37722013000400003

Pinto, A. R., Paracampo, C. C. P., \& Albuquerque, L. C. (2008). Efeitos de perda de reforçadores sobre o seguir regras em participantes flexíveis e inflexíveis. Revista Brasileira de Análise do Comportamento, 1, 111-125.

Skinner, B. F. (1969). Contingencies ofreinforcement: A theoretical analysis. New York: Appleton-Century-Crofts. 